ARTICLE

\title{
Synthesis of bio-based methylcyclopentadiene via direct hydrodeoxygenation of 3-methylcyclopent- 2-enone derived from cellulose
}

\author{
Yanting Liu (1) 1,2,6, Ran Wang (10) 1,3,6, Haifeng Qi ${ }^{1}$, Xiao Yan Liu (i] 1, Guangyi Li', Aiqin Wang (1) 1, \\ Xiaodong Wang ${ }^{1}$, Yu Cong (1) ${ }^{1}$, Tao Zhang (i) ${ }^{1,2,4 凶} \&$ Ning Li (i) ${ }^{1,4,5 凶}$
}

The exploration of highly efficient processes to convert renewable biomass to fuels and value-added chemicals is stimulated by the energy and environment problems. Herein, we describe an innovative route for the production of methylcyclopentadiene (MCPD) with cellulose, involving the transformation of cellulose into 3-methylcyclopent-2-enone (MCP) and subsequent selective hydrodeoxygenation to MCPD over a zinc-molybdenum oxide catalyst. The excellent performance of the zinc-molybdenum oxide catalyst is attributed to the formation of $\mathrm{ZnMoO}_{3}$ species during the reduction of $\mathrm{ZnMoO}_{4}$. Experiments reveal that preferential interaction of $\mathrm{ZnMoO}_{3}$ sites with the $\mathrm{C}=\mathrm{O}$ bond instead of $\mathrm{C}=\mathrm{C}$ bond in vaporphase hydrodeoxygenation of MCP leads to highly selective formations of MCPD (with a carbon yield of $70 \%$ ).

\footnotetext{
${ }^{1}$ CAS Key Laboratory of Science and Technology on Applied Catalysis, Dalian Institute of Chemical Physics, Chinese Academy of Sciences, 116023 Dalian, China. ${ }^{2}$ State Key Laboratory of Catalysis, Dalian Institute of Chemical Physics, Chinese Academy of Sciences, 116023 Dalian, China. ${ }^{3}$ University of Chinese Academy of Sciences, 100049 Beijing, China. ${ }^{4}$ iChEM (Collaborative Innovation Center of Chemistry for Energy Materials), Dalian Institute of Chemical Physics, Chinese Academy of Sciences, 116023 Dalian, China. ${ }^{5}$ Dalian National Laboratory for Clean Energy, 116023 Dalian, China. ${ }^{6}$ These authors contributed equally: Yanting Liu, Ran Wang. ${ }^{凶}$ email: taozhang@dicp.ac.cn; lining@dicp.ac.cn
} 
W ith the increment of social concern about energy and environmental problems, the exploration of technologies for the production of fuels ${ }^{1-5}$ and value-added chemicals $^{6-10}$ with renewable biomass has drawn a lot of attention. Methylcyclopentadiene (MCPD) is an important monomer in the production of RJ-4 fuel, a high-energy-density rocket fuel ${ }^{11}$. Meanwhile, it is also widely used in the synthesis of various valuable products (e.g., epoxy curing agent methylnadic anhydride (MNA), gasoline antiknock methylcyclopentadienyl manganese tricarbonyl (MMT), medicines, dye additives, organometallic catalysts, etc. $)^{12}$. Currently, MCPD is mainly obtained from the by-products of petroleum cracking tar at a very low yield $\left(\sim 0.7 \mathrm{~kg} \mathrm{ton}^{-1}\right)$ and high price $\left(\sim 10,000 \text { USD ton }^{-1}\right)^{12,13}$. This greatly limits its application. Previous studies have shown that the linalool can be converted to $\mathrm{MCPD}^{14}$. However, linalool is extracted from some special plants (such as lavender, rose, basil, and citrus aurantium, etc.) at low yields. From a practical point of view, the route for the synthesis of renewable MCPD with cheaper and more abundant biomass is highly expected. It is well-known that cellulosic biomass has the advantage of large availability, renew-ability, and $\mathrm{CO}_{2}$ neutral. Therefore, the development of strategies for the production of MCPD with cellulose will be of considerable significance because of its increasing market demand $\left(>50,000\right.$ tons year $\left.^{-1}\right)$ and limited petroleum resources. To the best of our knowledge, there is no report about the selective synthesis of MCPD via chemical conversion of cellulose.

Herein, we describe an approach to produce renewable MCPD from cellulose (Fig. 1). This process is an integrated technology that includes the hydrogenolysis of cellulose to 2,5-hexanedione (HD), the intramolecular aldol condensation of $\mathrm{HD}$ to 3methylcyclopent-2-enone (MCP), and subsequent hydrodeoxygenation of MCP to MCPD. The first two steps have been reported by literature ${ }^{15-18}$. In our recent work ${ }^{18}$, cellulose was selectively transformed into HD with a separation carbon yield of $71 \%$. The intramolecular aldol condensation of the cellulosederived HD produced MCP at a carbon yield of $98 \%$. Based on these results, a high overall carbon yield of $70 \%$ MCP was obtained from cellulose. As the focus and innovation of this work, we reported the direct synthesis of MCPD by the selective hydrodeoxygenation of MCP.

\section{Results}

Catalytic performance of metal oxide catalysts. As we know, the direct hydrodeoxygenation of unsaturated ketones to dienes is a reaction that has great commercial significance. However, this process is usually very challenging because the hydrogenation of $\mathrm{C}=\mathrm{C}$ bond in unsaturated ketones is preferred than the hydrogenation and/or cleaving of $\mathrm{C}=\mathrm{O}$ bond ${ }^{19}$. In the recent work of Román-Leshkov et al. ${ }^{20}$, a series of saturated ketones and aldehydes were hydrodeoxygenated to corresponding mono-olefins (or aromatics) over various slightly reducible metal oxides (e.g., $\mathrm{V}_{2} \mathrm{O}_{5}, \mathrm{MoO}_{3}, \mathrm{WO}_{3}, \mathrm{Fe}_{2} \mathrm{O}_{3}$, and $\mathrm{CuO}$ ). Among them, $\mathrm{MoO}_{3}$ exhibited the highest hydrodeoxygenation activity. It has been suggested that the hydrodeoxygenation of ketones to olefins over $\mathrm{MoO}_{3}$ follows a reverse Mars-van Krevelen mechanism, which includes the reaction of oxygen vacancy sites with the oxygenates to yield olefinic products and the regeneration of oxygen vacancy sites by $\mathrm{H}_{2}$ reduction ${ }^{21}$. Unfortunately, it was found that the pure $\mathrm{MoO}_{3}$ is not well suited for selective hydrodeoxygenation of MCP to MCPD. As we can see from Table 1 (entry 1 ), $\mathrm{MoO}_{3}$ catalyst suffers from a poor MCPD selectivity (18\%) as a result of the excessive hydrogenation of $\mathrm{C}=\mathrm{C}$ bond and the $\mathrm{C}-\mathrm{C}$ bond cleavage to form various by-products (such as methylcyclopentene (MCPE), hexadienes (HDE), hexenes (HE), etc.) (Supplementary Figs. 1-6). However, it is interesting that MCPD selectivity can be improved after loading $\mathrm{MoO}_{3}$ on some often used supports (e.g., $\mathrm{ZnO}, \mathrm{Al}_{2} \mathrm{O}_{3}, \mathrm{ZrO}_{2}$, and $\mathrm{SiO}_{2}$ ) by the impregnation method (Table 1, entries 2-5). Meanwhile, such a promotion effect is more evident when the commercial nano- $\mathrm{ZnO}$ with a specific Brunauer-Emmett-Teller (BET) surface area of $22 \mathrm{~m}^{2} \mathrm{~g}^{-1}$ is used as the support. Over the $\mathrm{MoO}_{3} / \mathrm{ZnO}$ catalyst, $71 \% \mathrm{MCPD}$ selectivity was attained at a $99 \%$ MCP conversion under the optimum reaction conditions (Table 1, entry 2 and Supplementary Fig. 8). As we can see from the $\mathrm{H}_{2}$ temperature-programmed reduction $\left(\mathrm{H}_{2}-\mathrm{TPR}\right)$ profiles (Supplementary Fig. 7 ), $\mathrm{MoO}_{3} / \mathrm{ZnO}$ exhibited the highest reduction temperature among the investigated catalysts. Therefore, we believe that the significantly higher MCPD selectivity over the $\mathrm{MoO}_{3} / \mathrm{ZnO}$ may be attributed to the strong interaction between $\mathrm{MoO}_{3}$ and $\mathrm{ZnO}$ support. To the best of our knowledge, this is the first report about the synthesis of MCPD via the direct hydrodeoxygenation of MCP from cellulose. Meanwhile, this work also opens up a horizon for the production of dienes with unsaturated ketone by a direct hydrodeoxygenation process.

For comparison, we also studied the catalytic performances of $\mathrm{ZnO}$ supported $\mathrm{V}_{2} \mathrm{O}_{5}, \mathrm{WO}_{3}, \mathrm{Fe}_{2} \mathrm{O}_{3}$, and $\mathrm{CuO}$ catalysts under the same reaction conditions (Table 1, entries 6-9). It was noticed that the MCP conversions and MCPD carbon yields over the $\mathrm{V}_{2} \mathrm{O}_{5} / \mathrm{ZnO}, \mathrm{WO}_{3} / \mathrm{ZnO}, \mathrm{Fe}_{2} \mathrm{O}_{3} / \mathrm{ZnO}$, and $\mathrm{CuO} / \mathrm{ZnO}$ catalysts are obviously lower than those over the $\mathrm{MoO}_{3} / \mathrm{ZnO}$ catalyst. Due to this reason, we concentrated on the $\mathrm{MoO}_{3} / \mathrm{ZnO}$ catalyst in the following research.

Relationship between catalyst structure and activity. To find out the intrinsic reason for the excellent catalytic performance of $\mathrm{MoO}_{3} / \mathrm{ZnO}$, we investigated the structure evolution of the Mo species during the preparation of the $\mathrm{MoO}_{3} / \mathrm{ZnO}$ catalyst. For the $\mathrm{MoO}_{3} / \mathrm{ZnO}$ catalyst precursor prepared by the impregnation of $\mathrm{ZnO}$ with ammonium heptamolybdate (AHM) solution, the Xray diffraction (XRD) patterns show well-resolved peaks corresponding to the $\mathrm{H}_{3} \mathrm{NH}_{4} \mathrm{Zn}_{2} \mathrm{Mo}_{2} \mathrm{O}_{10}$ species, as well as $\mathrm{ZnO}$ (Fig. 2a and Supplementary Fig. 9). Upon calcination at $600{ }^{\circ} \mathrm{C}$, the characteristic peaks associated with $\mathrm{H}_{3} \mathrm{NH}_{4} \mathrm{Zn}_{2} \mathrm{Mo}_{2} \mathrm{O}_{10}$ disappeared, indicating the decomposition of $\mathrm{H}_{3} \mathrm{NH}_{4} \mathrm{Zn}_{2} \mathrm{Mo}_{2} \mathrm{O}_{10}$ to $\mathrm{ZnMoO}_{4}$ (Fig. 2a and Supplementary Fig. 10). No obvious $\mathrm{MoO}_{3}$ peak was detected in both the XRD patterns and Raman spectra of $\mathrm{MoO}_{3} / \mathrm{ZnO}$ catalyst (Supplementary Figs. 10 and 11). The Xray absorption near-edge structure (XANES) spectrum at the Kedge of Mo species in the catalyst exhibits the same characteristics of reference $\mathrm{ZnMoO}_{4}$ compound (Fig. 2b), which is different from the AHM and $\mathrm{MoO}_{3}$ compounds. These results confirm that the Mo species exists mainly as the $\mathrm{ZnMoO}_{4}$ phase on the $\mathrm{ZnO}$

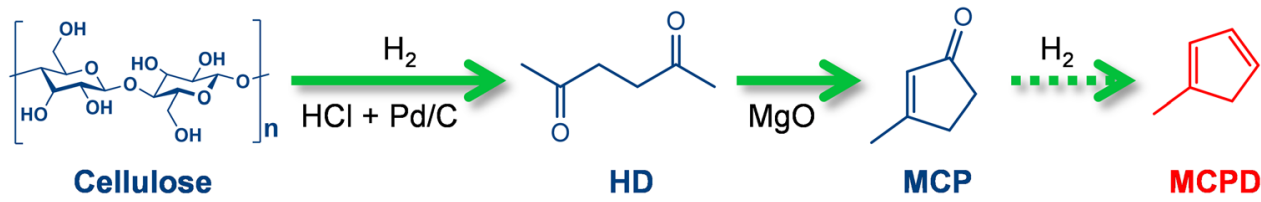

Fig. 1 Strategy for MCPD production from cellulose. By the selective hydrodeoxygenation of the $\mathrm{MCP}$ which can be obtained from the $\mathrm{HCl}+\mathrm{Pd} C$ catalyzed cellulose hydrogenolysis followed by the MgO catalyzed intramolecular aldol condensation, a high yield of MCPD was achieved in this work. 


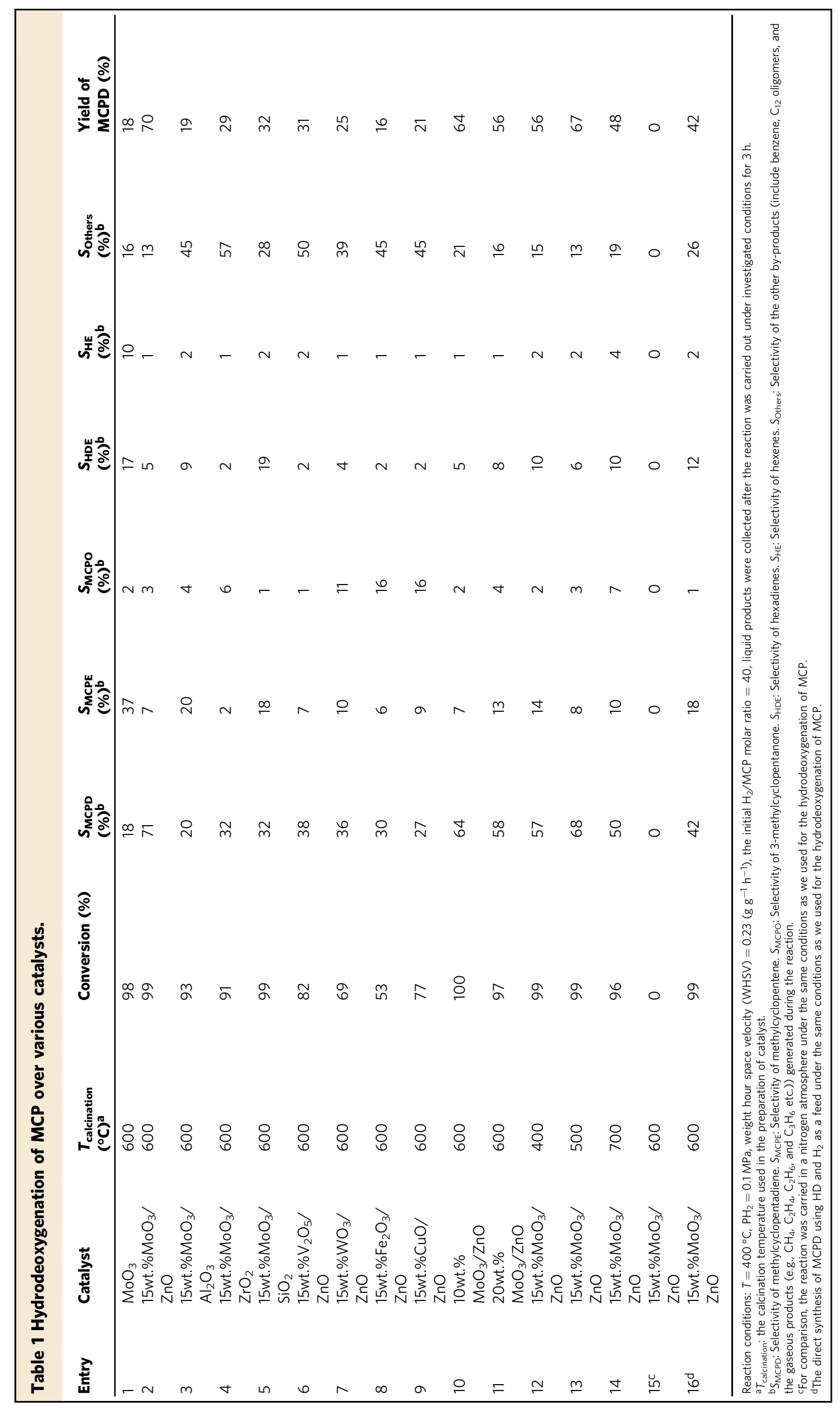



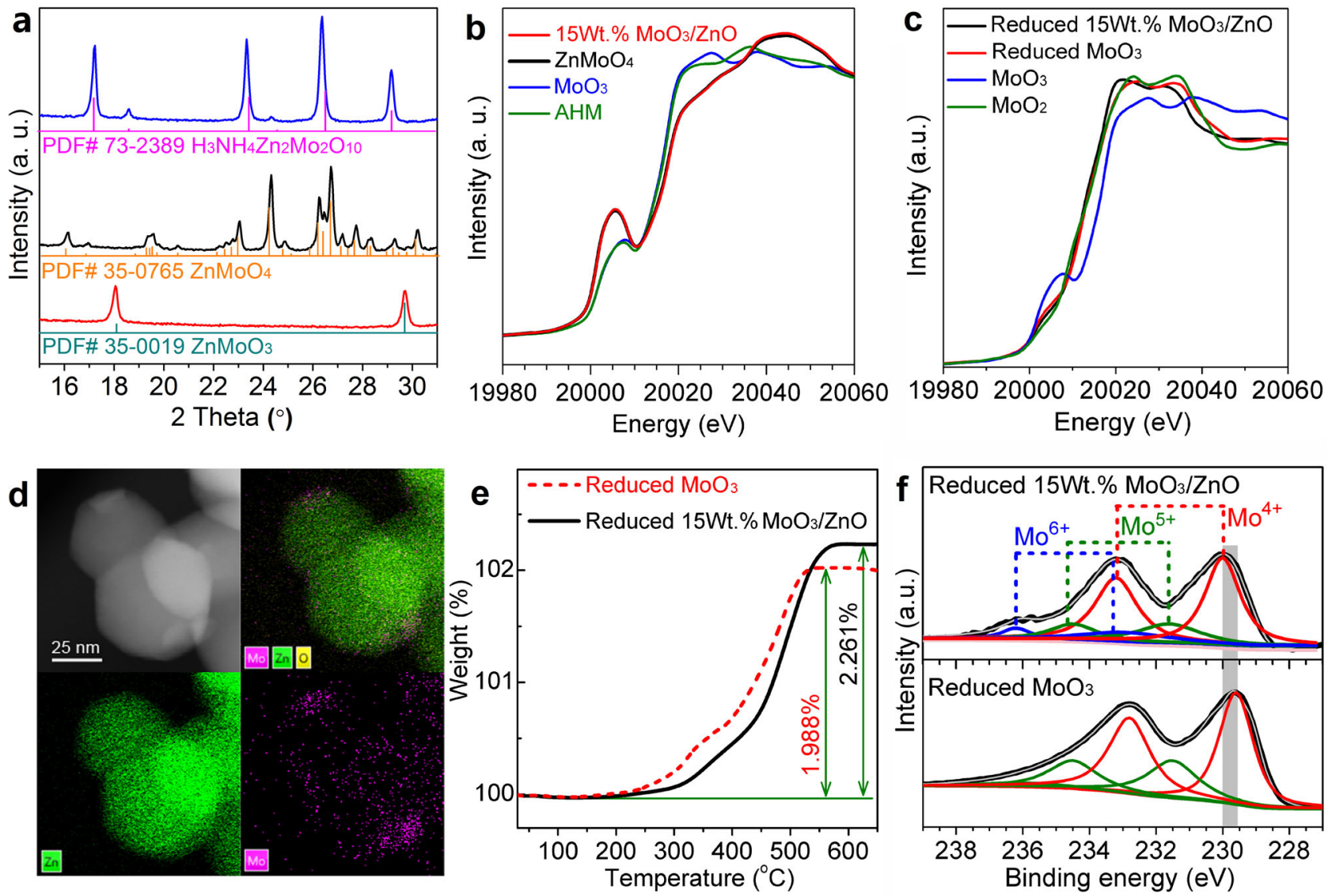

Fig. 2 Characterization results of catalysts. a XRD patterns of the as-prepared (blue line), calcined (black line), and reduced (red line) $15 \mathrm{wt} . \% \mathrm{MoO} / 3 / \mathrm{ZnO}$ catalysts. b Normalized XANES spectra at the $\mathrm{K}$-edge of $\mathrm{Mo}$ of the $15 \mathrm{wt} . \% \mathrm{MoO}_{3} / \mathrm{ZnO}$ catalyst and three reference compounds $\left(\mathrm{ZnMoO}, \mathrm{MoO}_{3}\right.$, and $\mathrm{AHM}$ ). c Normalized XANES spectra at the K-edge of $\mathrm{Mo}$ of the reduced $\mathrm{MoO}_{3}, 15 \mathrm{wt} . \% \mathrm{MoO}_{3} / \mathrm{ZnO}$ catalyst and two reference compounds ( $\mathrm{MoO} \mathrm{O}_{3}$ and $\mathrm{MoO}_{2}$ ). d STEM image and elemental mappings of the reduced $15 \mathrm{wt} . \% \mathrm{MoO}_{3} / \mathrm{ZnO}$ catalyst. e TG profiles of the reduced $\mathrm{MoO}_{3}$ and $15 \mathrm{wt} . \% \mathrm{MoO}_{3} / \mathrm{ZnO}$ catalysts in flowing air. $\mathbf{f o} 3 d$ core level XPS spectrum of the reduced $\mathrm{MoO}_{3}$ and $15 \mathrm{wt} . \% \mathrm{MoO}_{3} / \mathrm{ZnO}$ catalysts. $15 \mathrm{wt} . \% \mathrm{MoO}_{3} / \mathrm{ZnO}$ represents that the mass of Mo element in the catalyst accounts for $15 \%$ of the total mass.

support. After contacting with hydrogen under the reaction temperature of $400^{\circ} \mathrm{C}$, the XRD pattern showed that the $\mathrm{ZnMoO}_{4}$ peaks disappeared. Meanwhile, the $\mathrm{ZnMoO}_{3}$ peaks appeared at $18.1^{\circ}$ and $29.7^{\circ}$ (Fig. 2a and Supplementary Fig. 12). This result means that $\mathrm{ZnMoO}_{4}$ was gradually transformed into $\mathrm{ZnMoO}_{3}$ under reaction condition. The XANES spectra at the K-edge of Mo species in Fig. $2 \mathrm{c}$ indicated that the valance state of the Mo species in the reduced sample was close to that of the $\mathrm{MoO}_{2}$. At the same time, the peak at the pre-edge $(\sim 20,005 \mathrm{eV})$ ascribed to the distorted octahedral structure in the $\mathrm{MoO}_{3}$ sharply decreased, which indicated the structure of Mo species changed to the octahedral structure 22,23 . The extended X-ray absorption fine structure (EXAFS) data in $r$-space (Supplementary Fig. 13) and the data fitting results (Supplementary Table 1) showed that the average Mo-O distance in the first shell of the reduced $15 \mathrm{wt} . \%$ $\mathrm{MoO}_{3} / \mathrm{ZnO}$ is $2.06 \AA$, which is longer than those in the $\mathrm{MoO}_{2}$ $(2.02 \AA)$ and the reduced $\mathrm{MoO}_{3}(2.01 \AA)$. Besides, the corresponding coordination number of the Mo-O of the reduced $15 \mathrm{wt}$. $\% \mathrm{MoO}_{3} / \mathrm{ZnO}$ is 4.3 , which is lower than that of the reduced $\mathrm{MoO}_{3}$ (4.8). The above results indicated that the interaction between the $\mathrm{MoO}_{x}$ and $\mathrm{ZnO}$ leads to the expansion of the Mo-O distance and reduction of the Mo-O coordination in the first shell. The specific BET surface area of the $15 \mathrm{wt} . \% \mathrm{MoO}_{3} / \mathrm{ZnO}$ was measured as $19.2 \mathrm{~m}^{2} \mathrm{~g}^{-1}$, which is very close to that of $\mathrm{ZnO}$ support (Supplementary Table 2). Transmission electron microscopy (TEM) shows that the Mo species are uniformly dispersed on the $\mathrm{ZnO}$ nanoparticles (Fig. 2d).
For the deoxygenation catalyzed by the slightly reducible oxides, it is generally accepted that the oxy-compound is adsorbed on the oxygen vacancies of metal oxides ${ }^{20}$. Since the dissociation of $\mathrm{C}=\mathrm{O}$ bonds is a high barrier process, the oxygen vacancy concentrations of the oxides will directly decide their catalytic performances in the deoxygenation reaction. The degree of generating oxygen vacancies for the oxides after reduction for $2 \mathrm{~h}$ were evaluated by thermogravimetry (TG) in flowing air (Fig. 2e). The percentage of weight gain for the partially reduced $15 \mathrm{wt} . \% \mathrm{MoO}_{3} / \mathrm{ZnO}$ and $\mathrm{MoO}_{3}$ were measured as $2.261 \%$ and $1.988 \%$, respectively. From this result, we can see that the oxygen vacancy concentration of $15 \mathrm{wt} . \% \mathrm{MoO}_{3} / \mathrm{ZnO}$ is higher than that of $\mathrm{MoO}_{3}$. The interaction between the $\mathrm{MoO}_{x}$ and $\mathrm{ZnO}$ might promote the formation of the oxygen vacancies, as manifested by the EXAFS results in Supplementary Fig. 13 and Supplementary Table 1: the distance and the coordination number of $\mathrm{Mo}-\mathrm{O}$ in the first shell of the reduced $15 \mathrm{wt} . \% \mathrm{MoO}_{3} /$ $\mathrm{ZnO}$ are longer and lower respectively than the corresponding parameters of the reduced $\mathrm{MoO}_{3}$. If we calculated based on $\mathrm{Mo}$ species (In this calculation, the contribution of $\mathrm{ZnO}$ support was excluded because the oxygen vacancies generated by $\mathrm{ZnO}$ were negligible under conditions employed (Supplementary Fig. 14)), the oxygen vacancy concentrations of $15 \mathrm{wt} . \% \mathrm{MoO}_{3} / \mathrm{ZnO}$ $(10.049 \%)$ is $\sim 5$ times that of $\mathrm{MoO}_{3}(1.988 \%)$. This may be the reason why $15 \mathrm{wt} . \% \mathrm{MoO}_{3} / \mathrm{ZnO}$ catalyst is more selective for the hydrodeoxygenation of MCP to MCPD than bulk $\mathrm{MoO}_{3}$ (Table 1 , entries 1 and 2). 

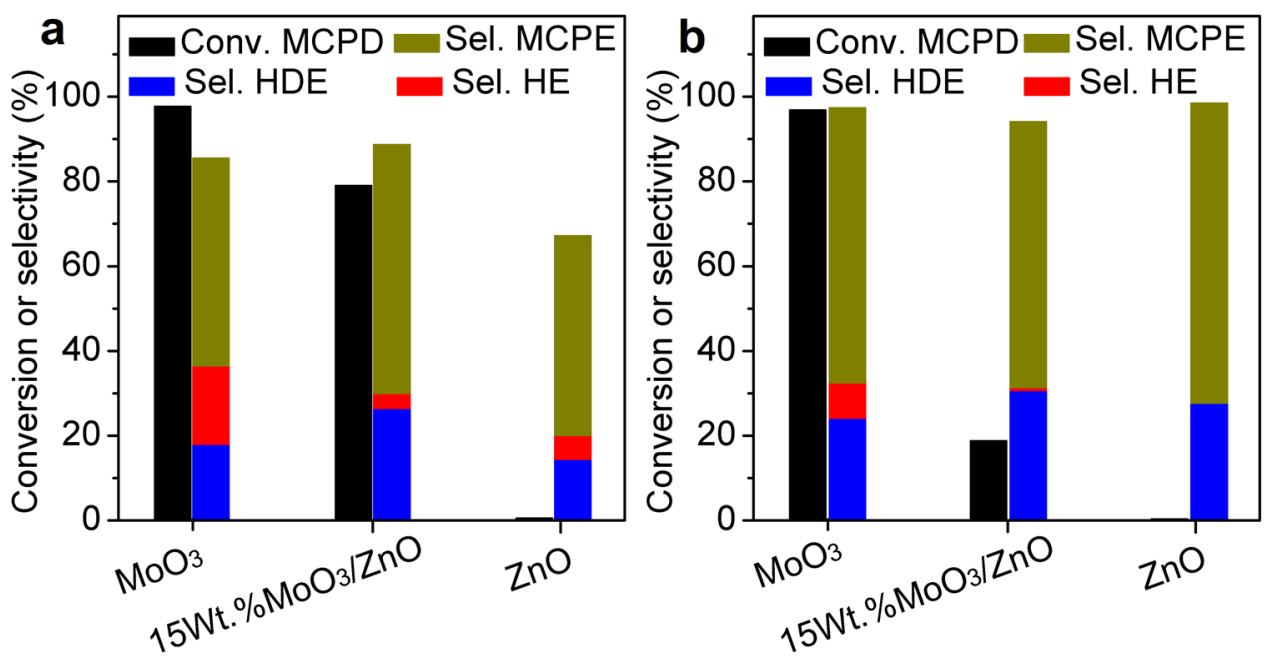

Fig. 3 Hydrogenation performance of various catalysts. a MCPD was used as feedstock, $\mathbf{b}$ acetone + MCPD (initial acetone/MCPD molar ratio $=1$ ) was used as feedstock. Conditions: $T=400^{\circ} \mathrm{C}, \mathrm{PH}_{2}=0.1 \mathrm{MPa}, \mathrm{WHSV}=0.23 \mathrm{~g} \mathrm{~g}^{-1} \mathrm{~h}^{-1}$, initial $\mathrm{H}_{2} / \mathrm{MCPD}$ molar ratio is 40 . MCPD methylcyclopentadiene, MCPE methylcyclopentene, HDE hexadienes, HE hexenes.

To further find out the reason for the high MCPD selectivity in the hydrodeoxygenation of $\mathrm{MCP}$ over the $15 \mathrm{wt} . \mathrm{MoO}_{3} / \mathrm{ZnO}$ catalyst, the electronic properties of surface Mo species of the partially reduced catalyst were investigated by X-ray photoelectron spectroscopy (XPS) (Fig. 2f). The peak fitting suggests that there are three oxidation states $(+4,+5$, and +6$)$ for Mo species on the surface of $15 \mathrm{wt} . \% \mathrm{MoO}_{3} / \mathrm{ZnO}$ catalyst ${ }^{24,25} . \mathrm{Mo}^{6+}$ is derived from unreduced $\mathrm{ZnMoO}_{4}$. Small $\mathrm{Mo}^{5+}$ peaks along with the dominant peaks of $\mathrm{Mo}^{4+}$ can be assigned to the partiallyreduced $\mathrm{ZnMoO}_{4}$ moieties and the coordinatively unsaturated sites of $\mathrm{ZnMoO}_{3}$, respectively. Compared with the binding energies (BE) of $\mathrm{Mo}^{4+}$ in the reduced $\mathrm{MoO}_{3}(229.5 \mathrm{eV})$, the higher $\mathrm{BE}$ in the reduced $15 \mathrm{wt} . \% \mathrm{MoO}_{3} / \mathrm{ZnO}(230.0 \mathrm{eV})$ indicates the lower electron density of Mo species, which may hinder the hydrogenation of $\mathrm{C}=\mathrm{C}$ bond and $\mathrm{C}-\mathrm{C}$ bond cleavage in the hydrodeoxygenation of $\mathrm{MCP}$, consequently lead to the higher MCPD selectivity (Table 1, entries 1 and 2).

Preferential adsorption of $\mathrm{C}=\mathrm{O}$ bond on catalyst. In addition to the hydrodeoxygenation of MCP, we also examined the hydrogenation of MCPD over the $15 \mathrm{wt} . \% \mathrm{MoO}_{3} / \mathrm{ZnO}, \mathrm{MoO}_{3}$, and $\mathrm{ZnO}$ catalysts to further illustrate how the electronic properties of catalysts influence their behaviors. As shown in Fig. 3a, $\mathrm{ZnO}$ support was almost inactive for the hydrogenation of MCPD under the investigated conditions. In contrast, both $15 \mathrm{wt} . \%$ $\mathrm{MoO}_{3} / \mathrm{ZnO}$ and $\mathrm{MoO}_{3}$ are highly active for the hydrogenation of MCPD. Over them, high MCPD conversions were observed, MCPE was formed as the major product (the conversions of MCPD over the $15 \mathrm{wt} . \% \mathrm{MoO}_{3} / \mathrm{ZnO}$ and $\mathrm{MoO}_{3}$ are $81 \%$ and $98 \%$, while the corresponding selectivities of MCPE are 59\% and $49 \%$, respectively). Based on this result, we cannot simply attribute the higher MCPD selectivity of $\mathrm{MoO}_{3} / \mathrm{ZnO}$ to its lower activity for the $\mathrm{C}=\mathrm{C}$ bond hydrogenation during hydrodeoxygenation of $\mathrm{MCP}$. Taking into consideration that $\mathrm{MCP}$ has $\mathrm{C}=\mathrm{C}$ bond and $\mathrm{C}=\mathrm{O}$ bond simultaneously, we believe that the higher selectivity for deoxygenation of MCP to MCPD over the $15 \mathrm{wt} . \% \mathrm{MoO}_{3} / \mathrm{ZnO}$ catalyst might be the result of energetically preferential adsorption of $\mathrm{C}=\mathrm{O}$ bond in presence of $\mathrm{C}=\mathrm{C}$ bond. To verify this hypothesis, acetone (a biomass-derived ketone, which has $\mathrm{C}=\mathrm{O}$ bond) was co-fed with $\mathrm{MCPD}$ over $15 \mathrm{wt} . \% \mathrm{MoO}_{3} / \mathrm{ZnO}, \mathrm{MoO}_{3}$, and $\mathrm{ZnO}$. As shown in Fig. 3b, the co-feeding of acetone had no evident influence on the MCPD conversion over $\mathrm{MoO}_{3}$, which means that $\mathrm{MoO}_{3}$ catalyst remains highly active for hydrogenation of $\mathrm{C}=\mathrm{C}$ bond in $\mathrm{MCPD}$ even in presence of $\mathrm{C}=\mathrm{O}$ bond (from acetone). In contrast, the presence of acetone significantly restrained the hydrogenation of MCPD over $15 \mathrm{wt} . \%$ $\mathrm{MoO}_{3} / \mathrm{ZnO}$. This may be one reason for the higher MCPD selectivity over the $15 \mathrm{wt} . \% \mathrm{MoO}_{3} / \mathrm{ZnO}$ catalyst for MCP hydrodeoxygenation.

In addition to acetone, the reaction with MCPD + 4-hexen-3one (a representative of $\alpha, \beta$-unsaturated carbonyl compound) as a reactant was investigated over the $15 \mathrm{wt} . \% \mathrm{MoO}_{3} / \mathrm{ZnO}$ catalyst. As shown in Supplementary Fig. 15, the presence of 4-hexen-3one significantly restrained the hydrogenation of MCPD, leading to a decrease of MCPD conversion from 79 to $17 \%$. The phenomenon is similar to what we observed when MCPD + acetone was used as a feedstock. As we know, $\mathrm{MCP}$ also has $\mathrm{C}=\mathrm{O}$ group. Its preferential adsorption over the $15 \mathrm{wt} . \% \mathrm{MoO}_{3} / \mathrm{ZnO}$ catalyst may prevent the further hydrogenation of MCPD (generated from the hydrodeoxygenation of MCP) to MCPE. As the result, a high MCPD yield (or selectivity) was achieved over the $\mathrm{MoO}_{3} / \mathrm{ZnO}$ catalyst. On the contrary, there is no such preferential adsorption over the $\mathrm{MoO}_{3}$, which may be attributed to the lower Mo $\mathrm{BE}$ on partially reduced $\mathrm{MoO}_{3} / \mathrm{ZnO}$ than that on partially reduced $\mathrm{MoO}_{3}$ as indicated by XANES and XPS results from Fig. 2c, f, Supplementary Fig. 13 and Supplementary Table 1. As the result, the MCPD selectivity over $\mathrm{MoO}_{3}$ is lower than that over $\mathrm{MoO}_{3} / \mathrm{ZnO}$.

To further simplify technology for the synthesis of MCPD with cellulose, HD (obtained by the direct hydrogenolysis of cellulose) and $\mathrm{H}_{2}$ were also used as a feed to directly produce MCPD under the same conditions as we used for the hydrodeoxygenation of MCP. Over the optimized $15 \mathrm{wt} . \% \mathrm{MoO}_{3} / \mathrm{ZnO}$ catalyst, $42 \%$ MCPD selectivity was attained at a 99\% HD conversion (Table 1, entry 16). This result means that the intramolecular aldol condensation of $\mathrm{HD}$ to $\mathrm{MCP}$ and the subsequent selective hydrodeoxygenation of MCP to MCPD can be integrated into a one-step process, which is advantageous in a real application. To further confirm this hypothesis, we also studied the aldol condensation of $\mathrm{HD}$ to $\mathrm{MCP}$ over the $15 \mathrm{wt} . \% \mathrm{MoO}_{3} / \mathrm{ZnO}$ catalyst using $\mathrm{N}_{2}$ as the carrier gas. Under the same conditions as we used for the conversion of $\mathrm{HD}$ to MCPD under $\mathrm{H}_{2}$ atmosphere, a $70.5 \%$ selectivity of MCP was achieved at a $53.5 \% \mathrm{HD}$ conversion (Supplementary Table 3). To the best of our knowledge, this is the first report about the direct synthesis of a cyclic diene with straight-chain diketone as well. 


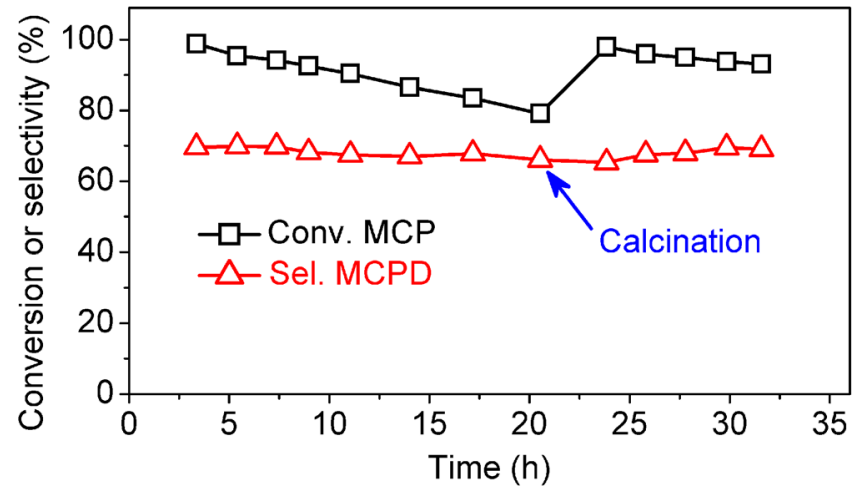

Fig. 4 The catalytic stability of $15 \mathrm{wt} . \% \mathrm{MoO}_{3} / \mathrm{ZnO}$ catalyst. Conditions: $T=400^{\circ} \mathrm{C}, \mathrm{PH}_{2}=0.1 \mathrm{MPa}, \mathrm{WHSV}=0.23 \mathrm{~g} \mathrm{~g}^{-1} \mathrm{~h}^{-1}$, initial $\mathrm{H}_{2} / \mathrm{MCP}$ molar ratio is 40. MCP 3-methylcyclopent-2-enone, MCPD

methylcyclopentadiene.

Stability of the catalyst. Finally, we also checked the stability of the $15 \mathrm{wt} . \% \mathrm{MoO}_{3} / \mathrm{ZnO}$ catalyst. During the $20 \mathrm{~h}$ time on steam (Fig. 4), the MCPD selectivity over the $15 \mathrm{wt} . \% \mathrm{MoO}_{3} / \mathrm{ZnO}$ catalyst kept constant, while the MCP conversion over the $15 \mathrm{wt} . \% \mathrm{MoO}_{3} /$ $\mathrm{ZnO}$ catalyst slightly decreased. Fortunately, such a problem can be overcome by regeneration. After being in situ calcined at $500^{\circ} \mathrm{C}$ for $2 \mathrm{~h}$ in flowing air and then reduced at $400{ }^{\circ} \mathrm{C}$ in $\mathrm{H}_{2}$ flow for 2 $\mathrm{h}$, the catalytic activity of deactivated $\mathrm{MoO}_{3} / \mathrm{ZnO}$ catalyst was almost restored to its initial level. Based on Supplementary Fig. 16, the spent $15 \mathrm{wt} . \% \mathrm{MoO}_{3} / \mathrm{ZnO}$ catalyst shows similar XRD patterns as the fresh one (after in situ reduction under the reaction conditions), which may be the reason for the stable MCPD selectivity over the $\mathrm{MoO}_{3} / \mathrm{ZnO}$ catalyst. The deactivation of $\mathrm{MoO}_{3} / \mathrm{ZnO}$ catalyst may be attributed to the formation of coke during the reaction because of the notable weight loss during calcination at high-temperature region $\left(380-500^{\circ} \mathrm{C}\right)$ indicated by TG in flowing air (Supplementary Fig. 17).

In summary, we have demonstrated a facile route for the synthesis of MCPD from cellulose. Firstly, MCP was obtained at $70 \%$ overall carbon yield from cellulose via our reported method. Subsequently, as the innovation of this work, MCPD was selectively obtained by the direct hydrodeoxygenation of MCP over a $15 \mathrm{wt} . \% \mathrm{MoO}_{3} / \mathrm{ZnO}$ catalyst. Based on the characterization results, the excellent performance of $\mathrm{MoO}_{3} / \mathrm{ZnO}$ catalyst could be ascribed to the formation of $\mathrm{ZnMoO}_{3}$ sites, which may preferentially adsorb $\mathrm{C}=\mathrm{O}$ bond in the presence of $\mathrm{C}=\mathrm{C}$ bond. As the result, a high yield of MCPD was obtained by the hydrodeoxygenation of MCP over the $\mathrm{MoO}_{3} / \mathrm{ZnO}$ catalyst. This work enables the synthesis of renewable MCPD with cheap and abundant cellulose from a practical point of view.

\footnotetext{
Methods

Materials. Analytical-grade 3-methylcyclopent-2-enone (MCP, 97\%) and ammonium heptamolybdate $\left(\left(\mathrm{NH}_{4}\right)_{6} \mathrm{Mo}_{7} \mathrm{O}_{24} \cdot 4 \mathrm{H}_{2} \mathrm{O}, 99 \%\right)$ were obtained from Shanghai Aladdin Bio-Chem Technology Co. and Tianjin Kermel Chemical Reagent Co, respectively. Commercially available nano- $\mathrm{ZnO}$ (ca. $\sim 20 \mathrm{~nm}$ ) were supplied by Nanjing Xianfeng nanometer material technology Co. LTD. $\mathrm{Al}_{2} \mathrm{O}_{3}, \mathrm{ZrO}_{2}$, and $\mathrm{SiO}_{2}$ supports were supplied by Shanghai Aladdin Bio-Chem Technology Co. The methylcyclopentadiene dimer (93\%) supplied by Shanghai Aladdin Bio-Chem Technology Co. was used for calibration after distilled under $160-170{ }^{\circ} \mathrm{C}$.

Preparation of catalysts. The $x \mathrm{MoO}_{3} / \mathrm{ZnO}(x$ denotes the theoretical Mo loading in weight percentage), $15 \mathrm{wt} . \% \mathrm{MoO}_{3} / \mathrm{Al}_{2} \mathrm{O}_{3}, 15 \mathrm{wt} . \% \mathrm{MoO}_{3} / \mathrm{ZrO}_{2}$, and $15 \mathrm{wt} . \%$ $\mathrm{MoO}_{3} / \mathrm{SiO}_{2}$ catalysts were prepared by the impregnation method. A typical procedure was as follows: A defined amount of supports (e.g., $\mathrm{ZnO}, \mathrm{Al}_{2} \mathrm{O}_{3}, \mathrm{ZrO}_{2}$, and $\left.\mathrm{SiO}_{2}\right)$ were added into an aqueous solution of $\left(\mathrm{NH}_{4}\right)_{6} \mathrm{Mo}_{7} \mathrm{O}_{24} \cdot 4 \mathrm{H}_{2} \mathrm{O}$. The mixture was stirred for $4 \mathrm{~h}$, dried at $120^{\circ} \mathrm{C}$ for $4 \mathrm{~h}$, and calcined at $400-700{ }^{\circ} \mathrm{C}$ for $1 \mathrm{~h}$ in flowing air. The $\mathrm{MoO}_{3}$ catalyst was prepared by the calcination of $\left(\mathrm{NH}_{4}\right)_{6} \mathrm{Mo}_{7} \mathrm{O}_{24} \cdot 4 \mathrm{H}_{2} \mathrm{O}$ at $600{ }^{\circ} \mathrm{C}$ for $1 \mathrm{~h}$ in flowing air.
}

Activity test. The hydrodeoxygenation of 3-methylcyclopent-2-enone (MCP) was carried out under atmospheric pressure in a fixed-bed reactor. The diagram of the reaction device used in MCP hydrodeoxygenation is shown in Supplementary Fig. 18. The tubular reactor used in this work was made of $316 \mathrm{~L}$ stainless steel. The length, inner diameter, and constant temperature height of the reactor were measured as $30,0.5$, and $10 \mathrm{~cm}$, respectively. For each test, $2.5 \mathrm{~g}$ of catalyst was used. The static bed layer height was measured as $2 \mathrm{~cm}$. Prior to the activity test, the catalysts were activated by hydrogen (at a gas flow rate of $90 \mathrm{~mL} \mathrm{~min}{ }^{-1}$ ) at $400{ }^{\circ} \mathrm{C}$ for $2 \mathrm{~h}$, and then MCP (at a liquid flow rate of $0.01 \mathrm{~mL} \mathrm{~min}^{-1}$ ) was introduced into the reactor by HPLC pump along with $\mathrm{H}_{2}$ (at a gas flow rate of $90 \mathrm{~mL} \mathrm{~min}^{-1}$ ) which acted as a reactant and carrier gas at the same time. The contact time of MCP on the catalysts was calculated as $42.67 \mathrm{~s}$.

The products passed through the reactor, cooled down to $0{ }^{\circ} \mathrm{C}$, and became two phases in a gas-liquid separator. A small number of gas-phase products such as methylcyclopentadiene (MCPD), methylcyclopentene (MCPE), hexadienes (HDE), and hexenes (HE), were analyzed on-line by an Agilent 7890B GC after passing through the back pressure regulator. According to the concentration of feed (or specific compound) in the gas-phase effluent products (measured with the on-line GC by an external standard method), the gas flow rate of the effluent gas, and reaction time, we calculated the mole amount of feed (or specific compound) in gas-phase products. The liquid-phase products such as MCPD, MCPE, 3methylcyclopentanone (MCPO), HDE, and hexenes HE were periodically drained from the separator and analyzed by a GC (Agilent $7890 \mathrm{~A}$ ) fitted with a $30 \mathrm{~m} \mathrm{HP}-5$ capillary column and an FID using 1,4-dioxane as the internal standard. According to the analysis results, we calculated the mole amount of feed (or specific compound) detected in the liquid-phase products. Thus, the conversion and selectivity of the reactions were calculated based on the analysis of gas-phase and liquid-phase products. The Agilent 6540 Accurate-MS spectrometer (Q-TOF) was used for products (e.g., methylcyclopentadiene (MCPD), methylcyclopentene (MCPE), 3-methylcyclopentanone (MCPO), hexadienes (HDE) and hexenes (HE)) identification. The conversion and the selectivity of the reactions were calculated based on the following equations: Conversion $(\%)=100-$ total mole amount of feed detected in gas-phase and liquid-phase products/mole amount of feed pumped into reactor $\times 100$; Selectivity for a specific compound $(\%)=$ total mole amount of a specific compound detected in the gas-phase and liquid-phase products/total mole amount of feed converted $\times 100$.

Characterization of catalysts. XRD patterns were obtained on a PANalytical X'Pert-Pro diffractometer using $\mathrm{Cu} K \alpha$ radiation $(\lambda=1.5406 \AA)$ at room temperature. Data points were acquired by step scanning at a rate of $10^{\circ} \mathrm{min}^{-1}$ from $2 \theta=10^{\circ}-90^{\circ}$. XRD patterns of reduced samples were tested by an in situ device. $\mathrm{N}_{2}$-physisorption tests of the investigated catalysts were carried out by an ASAP 2010 apparatus. Specific surface areas of the investigated catalysts were calculated by the Brunauer-Emmett-Teller (BET) method. Average pore volumes and average pore sizes of catalysts were estimated according to the Barrett-Joyner-Halenda (BJH) method. Transmission electron microscopy (TEM) images of the samples were collected by a JEM-2100F high-resolution transmission which was operated at $200 \mathrm{keV}$. Characterizations of X-ray photoelectron spectroscopy (XPS) were conducted on an ESCALAB250xi spectrometer. Prior to the measurements, each sample was pressed into a thin disk and reduced under $\mathrm{H}_{2}$ flow at $400{ }^{\circ} \mathrm{C}$ in an auxiliary pretreatment chamber. After the reduction, the obtained sample was directly introduced into the XPS chamber to avoid exposure to air. The XPS spectra were recorded at room temperature. The X-ray absorption spectra including X-ray absorption near-edge structure (XANES) and extended X-ray absorption fine structure (EXAFS) at the K-edge of Mo of the samples were collected at the BL 14W1 of Shanghai Synchrotron Radiation Facility (SSRF), China. The Mo foil was employed to calibrate the energy. The reduced samples were sealed in the glove box to protect them from contacting air. The spectra were collected at transmission mode at room temperature. The Athena software package was used to analyze the data. $\mathrm{H}_{2}$-temperature-programmed reduction (TPR) tests were carried out using a Micromeritics Autochem II 2920 automated chemisorption analyzer which was connected with an online mass spectrometer (MKS Cirrus 2). $0.1 \mathrm{~g}$ of sample was firstly calcined in air at $400{ }^{\circ} \mathrm{C}$ for $2 \mathrm{~h}$. Subsequently, the sample was cooled down in airflow to $30^{\circ} \mathrm{C}$. Finally, the sample was heated from $30^{\circ} \mathrm{C}$ to $800{ }^{\circ} \mathrm{C}$ at a rate of $10^{\circ} \mathrm{C} \mathrm{min}^{-1}$ in diluted hydrogen flow $\left(10 \% \mathrm{H}_{2}\right.$ in $\left.\mathrm{Ar}, 30 \mathrm{~mL} \mathrm{~min}^{-1}\right)$. Thermogravimetric (TG) analysis of $\mathrm{MoO}_{3}$ and $15 \mathrm{wt} . \% \mathrm{MoO}_{3} / \mathrm{ZnO}$ catalysts were carried out by the TA Instrument SDT Q 600 according to the following procedure. For the fresh $\mathrm{MoO}_{3}$ and $15 \mathrm{wt} . \% \mathrm{MoO}_{3} / \mathrm{ZnO}$ catalyst, the sample was reduced in hydrogen at $400^{\circ} \mathrm{C}$ for $2 \mathrm{~h}$ and swept with Ar flow at that temperature for $0.5 \mathrm{~h}$. Subsequently, the sample was cooled down to $30^{\circ} \mathrm{C}$ in flowing Ar. Finally, the reduced sample was heated in flowing air $\left(100 \mathrm{~mL} \mathrm{~min}^{-1}\right)$ from $30^{\circ} \mathrm{C}$ to $800{ }^{\circ} \mathrm{C}$ at a rate of $10^{\circ} \mathrm{C} \mathrm{min}-1$. For the used $15 \mathrm{wt} . \% \mathrm{MoO}_{3} / \mathrm{ZnO}$ catalyst (reaction conditions: $T=400^{\circ} \mathrm{C}, \mathrm{PH}_{2}=0.1 \mathrm{MPa}, \mathrm{WHSV}=0.23 \mathrm{~g} \mathrm{~g}^{-1} \mathrm{~h}^{-1}$, initial $\mathrm{H}_{2} / \mathrm{MCPD}$ molar ratio $=40$, time on stream $=20 \mathrm{~h}$ ), the sample was directly heated in flowing air $\left(100 \mathrm{~mL} \mathrm{~min}^{-1}\right)$ from 30 to $800^{\circ} \mathrm{C}$ at a rate of $10^{\circ} \mathrm{C} \mathrm{min}^{-1}$.

\section{Data availability}

The data that support the findings of this study are available within the paper and its Supplementary Information and all data are available from the authors on reasonable request. 
Received: 1 July 2020; Accepted: 20 November 2020;

Published online: 04 January 2021

\section{References}

1. Huber, G. W., Iborra, S. \& Corma, A. Synthesis of transportation fuels from biomass: Chemistry, catalysts, and engineering. Chem. Rev. 106, 4044-4098 (2006).

2. Shylesh, S., Gokhale, A. A., Ho, C. R. \& Bell, A. T. Novel strategies for the production of fuels, lubricants, and chemicals from biomass. Acc. Chem. Res. 50, 2589-2597 (2017).

3. Huber, G. W., Chheda, J. N., Barrett, C. J. \& Dumesic, J. A. Production of liquid alkanes by aqueous-phase processing of biomass-derived carbohydrates. Science 308, 1446-1450 (2005).

4. Cao, Z., Dierks, M., Clough, M. T., Daltro de Castro, I. B. \& Rinaldi, R. A convergent approach for a deep converting lignin-first biorefinery rendering high-energy-density drop-in fuels. Joule 2, 1118-1133 (2018).

5. Dong, L. et al. Breaking the limit of lignin monomer production via cleavage of interunit. Carbon Carbon Link. Chem. 5, 1521-1536 (2019).

6. Besson, M., Gallezot, P. \& Pinel, C. Conversion of biomass into chemicals over metal catalysts. Chem. Rev. 114, 1827-1870 (2014).

7. Roman-Leshkov, Y., Barrett, C. J., Liu, Z. Y. \& Dumesic, J. A. Production of dimethylfuran for liquid fuels from biomass-derived carbohydrates. Nature 447, 982-985 (2007).

8. Scodeller, I. et al. Synthesis of renewable meta-xylylenediamine from biomassderived furfural. Angew. Chem. Int. Ed. 57, 10510-10514 (2018).

9. Deng, W. et al. Catalytic amino acid production from biomass-derived intermediates. Proc. Natl Acad. Sci. USA 115, 5093-5098 (2018).

10. Liao, Y. et al. A sustainable wood biorefinery for low-carbon footprint chemicals production. Science 367, 1385 (2020).

11. Zhang, X., Pan, L., Wang, L. \& Zou, J.-J. Review on synthesis and properties of high-energy-density liquid fuels: hydrocarbons, nanofluids and energetic ionic liquids. Chem. Eng. Sci. 180, 95-125 (2018).

12. Lan, D. et al. Methylation of cyclopentadiene on solid base catalysts with different surface acid-base properties. J. Catal. 275, 257-269 (2010).

13. Claus, M. et al. ULLMANN'S Encyclopedia of Industrial Chemistry 1-16 (Wiley-VCH Verlag GmbH \& Co. KGaA, 2016).

14. Meylemans, H. A., Quintana, R. L., Goldsmith, B. R. \& Harvey, B. G. Solventfree conversion of linalool to methylcyclopentadiene dimers: a route to renewable high-density fuels. ChemSusChem 4, 465-469 (2011).

15. Chambon, F. et al. Conversion of cellulose to 2,5-hexanedione using tungstated zirconia in hydrogen atmosphere. Appl. Catal. A 504, 664-671 (2015).

16. Sun, D. L., Chiba, S., Yamada, Y. \& Sato, S. Vapor-phase intramolecular aldol condensation of 2,5-hexanedione to 3-methylcyclopent-2-enone over $\mathrm{ZrO}_{2-}$ supported $\mathrm{Li}_{2} \mathrm{O}$ catalyst. Catal. Commun. 92, 105-108 (2017).

17. Nishimura, S., Ohmatsu, S. \& Ebitani, K. Selective synthesis of 3-methyl-2cyclopentenone via intramolecular aldol condensation of 2,5-hexanedione with $\gamma-\mathrm{Al}_{2} \mathrm{O}_{3} / \mathrm{AlOOH}$ nanocomposite catalyst. Fuel Process. Technol. 196 106185 (2019).

18. Liu, Y. et al. Integrated conversion of cellulose to high-density aviation fuel. Joule 3, 1028-1036 (2019).

19. Gallezot, P. \& Richard, D. Selective hydrogenation of $\alpha, \beta$-unsaturated aldehydes. Catal. Rev. Sci. Eng. 40, 81-126 (1998).

20. Prasomsri, T., Nimmanwudipong, T. \& Roman-Leshkov, Y. Effective hydrodeoxygenation of biomass-derived oxygenates into unsaturated hydrocarbons by $\mathrm{MoO}_{3}$ using low $\mathrm{H}_{2}$ pressures. Energy Environ. Sci. 6 , 1732-1738 (2013).

21. Mars, P. \& van Krevelen, D. W. Oxidations carried out by means of vanadium oxide catalysts. Chem. Eng. Sci. 3, 41-59 (1954).

22. Ressler, T., Wienold, J., Jentoft, R. E. \& Neisius, T. Bulk structural investigation of the reduction of $\mathrm{MoO}_{3}$ with propene and the oxidation of $\mathrm{MoO}_{2}$ with oxygen. J. Catal. 210, 67-83 (2002).
23. Patridge, C. J., Whittaker, L., Ravel, B. \& Banerjee, S. Elucidating the influence of local structure perturbations on the metal-insulator transitions of $\mathrm{V}_{1-\mathrm{x}} \mathrm{Mo}_{\mathrm{x}} \mathrm{O}_{2}$ nanowires: mechanistic insights from an X-ray absorption spectroscopy study. J. Phys. Chem. C 116, 3728-3736 (2012).

24. Bara, C. et al. Aqueous-phase preparation of model HDS catalysts on planar alumina substrates: support effect on Mo adsorption and sulfidation. J. Am. Chem. Soc. 137, 15915-15928 (2015).

25. Nolte, M. W., Saraeian, A. \& Shanks, B. H. Hydrodeoxygenation of cellulose pyrolysis model compounds using molybdenum oxide and low pressure hydrogen. Green. Chem. 19, 3654-3664 (2017).

\section{Acknowledgements}

This work was supported by the National Natural Science Foundation of China (nos. 21776273; 21721004; 21690082), DICP (Grant: DICP I201944), DNL Cooperation Fund, CAS (DNL180301), the Strategic Priority Research Program of the Chinese Academy of Sciences (XDB17020100), the National Key Projects for Fundamental Research and Development of China (2016YFA0202801). The authors also appreciate the help from BL 14W beamline at the Shanghai Synchrotron Radiation Facility (SSRF), Shanghai, China.

\section{Author contributions}

Y.L. and R.W. contributed equally to this work. Y.L. and R.W. performed the catalyst preparation, characterizations, and activity tests. H.Q. collected the EXAFS data. X.L., G.L., A.W., X.W., and Y.C. analyzed the results. N.L. and T.Z. conceived the overall direction of the project. Y.L., N.L., and T.Z. co-wrote the paper. All the authors discussed the results and provided input for the manuscript.

\section{Competing interests}

The authors declare no competing interests.

\section{Additional information}

Supplementary information is available for this paper at https://doi.org/10.1038/s41467020-20264-3.

Correspondence and requests for materials should be addressed to T.Z. or N.L.

Peer review information Nature Communications thanks Satoshi Sato, Lauri Vares and the other, anonymous, reviewer(s) for their contribution to the peer review of this work. Peer reviewer reports are available.

Reprints and permission information is available at http://www.nature.com/reprints

Publisher's note Springer Nature remains neutral with regard to jurisdictional claims in published maps and institutional affiliations.

Open Access This article is licensed under a Creative Commons Attribution 4.0 International License, which permits use, sharing, adaptation, distribution and reproduction in any medium or format, as long as you give appropriate credit to the original author(s) and the source, provide a link to the Creative Commons license, and indicate if changes were made. The images or other third party material in this article are included in the article's Creative Commons license, unless indicated otherwise in a credit line to the material. If material is not included in the article's Creative Commons license and your intended use is not permitted by statutory regulation or exceeds the permitted use, you will need to obtain permission directly from the copyright holder. To view a copy of this license, visit http://creativecommons.org/ licenses/by/4.0/.

(C) The Author(s) 2021 